\title{
PERSEPSI KESESUAIAN DAN KEPUASAN PENGGUNAAN MEDIA SOSIAL PADA PERKULIAHAN: PENGUJIAN MODEL
}

Kurniabudi $^{1}$, Setiawan Assegaf ${ }^{2}$

\author{
${ }^{12}$ STIKOM Dinamika Bangsa \\ Email: ${ }^{1}$ kbudiz@ stikom-db.ac.id, ${ }^{2}$ setiawanassegaff@stikom-db.ac.id
}

(Naskah masuk: 05 Juli 2018, diterima untuk diterbitkan: 02 November 2018)

\begin{abstract}
Abstrak
Penerimaan teknologi merupakan faktor penting, untuk keberlanjutan penggunaan sebuah teknologi. Model-model pengukuran telah banyak dikembangkan, namun belum mempertimbangkan kesesuaian dan kepuasan dalam penggunaan teknologi berkelanjutan. Pada penelitian yang sebelumnya penulis telah mengembangkan model kepuasan dan kesesuaian (Task-fit and Satisfaction Model) untuk mengidentifikasi persepsi dosen terhadap kesesuaian dan kepuasan penggunaan facebook sebagai sarana komunikasi dan informasi pada perkuliahan, namun belum diuji. Artikel ini menyajikan proses pengujian terhadap model tersebut. Responden penelitian ini adalah dosen di indonesia khususnya yang menggunakan facebook. Data penelitian dikumpulkan dengan menggunakan metode survey online. Metode Structural Equation Modeling (SEM) dan Partial Least Square (PLS) digunakan untuk analisis data. Hasil pengujian hipotesis memperlihatkan perceived task-fit, utilization dan satisfaction secara signifikan mempengaruhi continuance intention. Pengujian juga memperlihatkan bahwa Perceived task fit , confirmation, dan Service quality secara signifikan mempengaruhi satisfaction. Terdapat korelasi positif perceived task-fit terhadap utilization, dan service quality terhadap confirmation. Sedangkan pengujian coefficient of determination $\left(R^{2}\right)$, memperlihatkan continuance intention memperoleh nilai $\mathrm{R}^{2}=0.723$, hal ini menunjukkan bahwa perentasi besarnya kemampuan model dalam memprediksi persepsi kesesuaian dan kepuasan dosen terhadap penggunaan facebook dalam perkuliahan sebesar $72.3 \%$.
\end{abstract}

Kata kunci: model kepuasan, kesesuaian, media sosial, adopsi teknologi

\section{PERCEIVED OF FITNESS AND SATISFACTION OF SOCIAL MEDIA USE ON LECTURES: TESTING MODEL}

\begin{abstract}
Acceptance of technology is an important factor, for the continued use of a technology. Measurement models have been developed, but not many consider perceived of fitness and satisfaction in receiving technology. In the previous research the authors has developed a Task-fit and Satisfaction Model to identify lecturers' perceptions of the suitability and satisfaction of facebook usage as a means of communication and information on lectures, the model have not test yet. This paper aim to present the testing process for this model. Responden this research is a lecturer in Indonesia especially who use facebook. Data collected by online survey method. SEM with PLS approach used to data analysis. The results of hypothesis testing show that perceived task-fit, utilization and satisfaction significantly influence continuance intention. The results also show that Perceived task fit, confirmation, and Service quality significantly affect satisfaction. There is a positive correlation of perceived task-fit to utilization, and service quality to confirmation. While the coefficient of determination test, shows continuance intention obtained the value of $R 2=0.723$, This shows that the magnitude of the model's ability to predict perceptions of fitness and lecturer satisfaction towards the use of Facebook in lectures is $72.3 \%$.
\end{abstract}

Keywords: satisfaction model, fitness, social media, technology adoption

\section{PENDAHULUAN}

Saat ini penggunaan media sosial tidak hanya sebatas sarana berkomunikasi dengan kolega. Namun dengan fitur-fitur yang disediakan oleh penyedia layanan media sosial seperti jejaring sosial memungkinkan pengguna untuk berbagi informasi. Sehingga hal ini membuka peluang untuk memanfaatkan media sosial sarana pendukung dalam pendidikan, seperti sebagai sarana komunikasi guru dan siswa atau dosen dan mahasiswa, berkolaborasi, berbagi file materi pembelajaran, membentuk grupgrup diskusi dan lain-lain(Silius, Kailanto, \& Tervakari, 2011). Hadirnya media sosial didunia pendidikan dan dampaknya bagi pendidikan tentu menjadi hal yang menarik untuk diteliti. Seperti Tess (Tess, 2013) meneliti tentang peran media sosial di 
perguruan tinggi. (Dragana, Arsic, Manasijevic, \& Miloševic, 2015) meneliti tentang faktor-faktor yang memotivasi adopsi media sosial dalam pembelajaran. Sebagaimana telah diketahui peran TIK (Teknologi Informasi dan Komunikasi) dalam pembelajaran memberikan banyak manfaat. Salah satunya mempermudah interaksi siswa dengan guru. Hal senada disampaikan oleh (Herlambang \& Hidayat, 2016), pemanfaatan TIK dalam pembelajaran asinkron dapat meningkatkan kemampuan siswa berkomunikasi, problem solving, dan cara berpikir yang reflektif, kritis, kreatif dan inovatif. Pada dasarnya penelitian ini berkaitan erat dengan adopsi atau penerimaan teknologi, dan bukan merupakan penelitian yang baru, penelitian ini telah banyak dikembangkan salah satunya oleh (Pradana, Rachmadi, \& Bachtiar, 2015), mengidentifikasi faktor penerimaan teknologi blended-learning. Kumar dkk. (Kumar, Joshi, \& Sharma, 2016) Memprediksi faktor penentu siswa menggunakan facebook dalam pembelajaran.

Di Indonesia, aktivitas penggunaan internet yang terbesar adalah mengakses jejaring sosial, hal ini berdasarkan data statistik Kementrian Komunikasi dan Informasi Republik Indonesia, melalui website statistik.kominfo.go.id pada tahun 2016 yaitu 73.30\%. Facebook merupakan jejaring sosial yang memiliki sisi positif dan negatif bagi pengguna, masalahnya tidak terdapat pada teknologinya namun lebih khusus pada pengguna (Kopecky, 2016). Sedangkan (Lambic, 2016) menunjukkan bahwa terdapat korelasi positif penggunaan facebook untuk keperluan pendidikan dengan peforma akademik siswa. Dalam penelitian (Zivkovi, Arsi, \& Milo, 2016) memaparkan bahwa siswa menggunakan facebook untuk keperluan berbagi informasi, membuat grup diskusi dan berkolaborasi.

Disisi lain penggunaan berkelanjutan sebuah teknologi sangat bergantung pada penerimaan teknologi tersebut. Penerimaan tenologi dapat dipengaruhi oleh kepuasan terhadap penggunaan teknologi untuk mendukung pekerjaan dan kesesuaian teknologi untuk menyelesaikan pekerjaan. Meskipun banyak studi yang berhubungan dengan model penggunaan teknologi secara berkelanjutan, namun belum mempertimbangkan masalah kepuasan dan kesesuaian teknologi dengan pekerjaan dalam sebuah model. Karena itu diperlukan sebuah model yang mampu mengukur persepsi kesesuaian dan kepuasan terhadap penggunaan berkelanjutan teknologi sosial media dalam perkuliahan.

Pada penelitian terdahulu peneliti telah mengembangkan model kepuasan dan kesesuaian penggunaan facebook sebagai sarana informasi dan komunikasi pada perkuliahan. Dimana model dikembangkan berdasarkan teori Task-Technology Fit dan Expectation Confirmation Theory atau disebut sebagai Task-fit and Satisfaction Model (TaSM). Model yang dikembangkan terdiri diri atas 6 (enam) konstruk yaitu : Perceived Task Fit (TF),
Utilization (UT), Confirmation (CF), Service Quality $(S Q)$, Satisfaction $(S F)$ dan Continuance Intention (CI). Model yang dikembangkan bertujuan memprediksi penggunaan teknologi informasi secara berkesinambungan dengan persfektif kesesuaian teknologi dan kepuasan penggunaan teknologi. Namun model tersebut belum diuji. Oleh karena itu artikel ini menyajikan proses pengujian Task-fit and Satisfaction Model yang telah dikembangkan pada penelitian sebelumnya. Pengujian akan dilakukan terhadap kemampuan model dalam mengidentifikasi kesesuaian dan kepuasan penggunaan facebook dalam perkuliahan. Pada artikel ini penulis hanya membahas tentang persepsi dosen.

\section{TEORI TERKAIT}

\subsection{Facebook}

Sebagaimana kita ketahui facebook merupakan salah satu aplikasi jejaring sosial yang paling banyak dikenal (Dragana et al., 2015), seperti dimuat pada smallbiztrends.com tahun 2016 Facebook menempati posisi teratas untuk media sosial yang paling popular. Aplikasi Facebook dirancang oleh Mark Zuckerberg mahasiswa Harvard University, pada awalnya hanya untuk dilingkungan kampus saja(Hew, 2011).

Sebagai aplikasi jejaring sosial facebook dilengkapi fasilitas-fasilitas untuk mengirim pesan, menambah teman, memperbarui profil pribadi, membuat aplikasi, bergabung dengan grup dan mengenal pengguna lain melalui profil mereka (Tess, 2013). Facebook dapat juga sebagai sarana hiburan seperti bermain games(Hew, 2011). Dengan segala potensi yang dimiliki, maka facebook juga dapat digunakan untuk keperluan pendidikan. Facebook merupakan media sosial yang banyak digunakan oleh siswa, dengan facebook dapat menciptakan kelas virtual. (Dragana et al., 2015). Melalui facebook dapat menciptakan grup-grup diskusi (Akcaoglu \& David, 2016).

\subsection{Task-fit and Satisfaction Model}

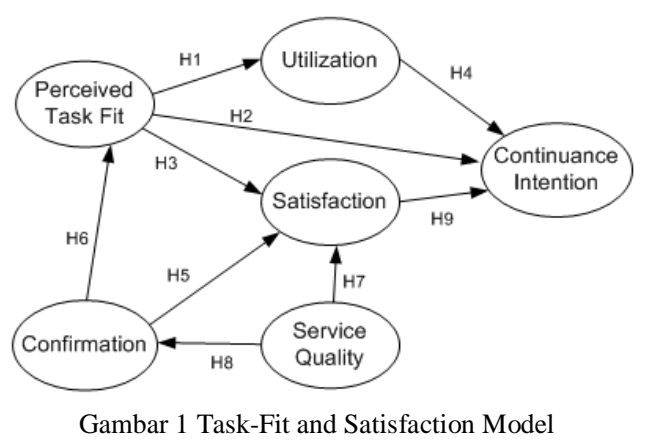

Pada penelitian terdahulu telah dikembangkan model kesesuaian dan kepuasan penggunaan teknologi informasi. TaSM dikembangkan berdasarkan teori Task-Technology Fit dan Expectation Confirmation Theory. Gambar 1 adalah model TaSM yang diusulkan pada penelitian terdahulu. 
- Perceived Task-fit, variabel ini diadopsi dari TTF, yang didefenisikan sebagai tingkat teknologi dapat membantu individu menyelesaikan tugasnya (Goodhue, L., \& Thompson, 1995). Digunakan untuk mengukur seberapa jauh teknologi yang digunakan secara fungsional sesuai untuk menyelesaikan pekerjaan pengguna (Holzinger, Searle, \& Wernbacher, 2011)(Lin, 2012).

- Utilization, digunakan untuk mengukur tingkat penggunaan teknologi untuk menyelesaikan tugas(Goodhue et al., 1995).Menurut (Yen, Wu, Cheng, \& Huang, 2010), dapat dipertimbangkan sebagai intention to use, Yaitu niat pengguna untuk menggunakan teknologi.

- Satisfaction, variabel ini diadopsi dari ECT, didefenisikan sejauh mana pengguna yakin bahwa teknologi dapat memenuhi kebutuhan mereka(Cheok \& Wong, 2015).

- Confirmation, didefenisikan sebagai sejauh mana pengalaman aktual pengguna sesuai dengan apa yang diharapkan(Bhattacherjee, 2001)(Venkatesh, Thong, Chan, Hu, \& Brown, 2011).

- Service Quality, variabel ini diadopsi dari perceived performance. Didasari atas teori (Liao, Chen, \& Yen, 2007) bahwa perceived performance dibagi menjadi perceived quality dan perceived usability. Pada model ini digunakan Service Quality yang didefenisikan sebagai kualitas dukungan yang diterima oleh pengguna dari penyedia layanan atau departemen IT(DeLone \& McLean, 2003)(Petter, DeLone, \& McLean, 2008).

- Continuance Intention, didefenisikan sebagai niat untuk menggunakan terus teknologi atau sistem(Shiau, Huang, \& Shih, 2011)(Patricks, Libaque-saenz, Fan, \& Chang, 2016).

Berdasarkan model pada gambar 1. pada penelitian sebelumnya penulis merumuskan hipotesis sebagai berikut :

- H1 : Perceived Task-Fit memiliki pengaruh terhadap Utilization

- H2 : Perceived Task-Fit memiliki pengaruh terhadap Continuante Intention.

- H3 : Perceived Task-Fit memiliki pengeruh terhadap Satisfaction

- H4 : Utilization memiliki pengaruh terhadap Continuance Intention

- H5 : Confirmation memiliki pengaruh terhadap Satisfaction

- H6 : Confirmation memiliki pengaruh terhadap Perceived Task Fit

- $H 7$ : Service Quality memiliki pengaruh signifikan terhadap Satisfaction

- H8 : Service Quality memiliki pengaruh sigfnifikan terhadap Confirmation
- $\quad H 9$ : Satisfaction memiliki pengaruh signifikan terhadap Continuance Intention

\subsection{Structural Equation Modeling (SEM)}

SEM sering digunakan pada penelitian multivariat. Merupakan salah satu metode statistik digunakan untuk memvalidasi atau menganalisa struktur atau relasi antar variabel pada sebuah model. (Buhi, Goodson, \& Neilands, 2007). SEM telah menjadi sebuah teknik yang dipilih oleh penelitipeneliti inter-disiplin ilmu (Hooper, Mullen, Hooper, Coughlan, \& Mullen, 2008), SEM juga secara luas digunakan pada penelitian dibidang Sistem Informasi (Urbach \& Ahlemann, 2010). SEM menggabungkan antara analisis faktor dengan analisis jalur. Pengujian hubungan antar variabel secara simultan dimungkinkan dengan menggunakan SEM.

\section{METODOLOGI PENELITIAN}

Untuk validasi model dilakukan melalui

beberapa tahapan yaitu :

- Pengumpulan Data.

Data penelitian diperoleh melalui survey online. Yang menjadi target responden adalah dosen di Indonesia, khususnya yang menggunakan facebook. Alamat tautan kuesioner disebarkan melalui Forum Dosen Muda Indonesia yang ada di facebook.

- Validasi Model

Pada tahapan ini dilakukan validasi Model, untuk memastikan bahwa model hasil modifikasi dapat digunakan untuk memprediksi kepuasan dan ketepatan penggunaan facebook sebagai sarana informasi dan komunikasi pada perkuliahan. Validasi meliputi : validasi model pengukuran dan struktur model.

- Interpretasi

Pada tahapan ini dilakukan interpretasi data. Interpretasi data mengacu pada hasil analisis data menggunakan SEM dan PLS.

\section{HASIL DAN PEMBAHASAN}

Pada bagian ini didiskusikan tentang hasil validasi dan analisa terhadap model yang yang diusulkan pada penelitian sebelumnya. Dimana telah dijelaskan pada bab sebelumnya bahwa pada penelitian sebelumnya, penulis telah merancang model Task-fit and Satisfaction Model (TaSM). Pada bagian ini akan dipaparkan tentang responden penelitian dan validasi model pengukuran dan validasi struktur model. Analisa menggunakan Structural Equation Model (SEM) dengan Partial Least Square (PLS). Menggunakan SEM dilakukan 2 (dua) pengujian yang disebut structural models (atau inner model) dan measurement models (atau outer model) (Urbach \& Ahlemann, 2010).

\subsection{Data Responden}

Untuk keperluan validasi, pada tahap pertama dilakukan pengumpulan data. Penentuan sampel menggunakan purposive sampling (Adamovic, 
Potgieter, \& Mearns, 2012). Teknik ini digunakan agar responden yang dipilih sesuai dengan karakteristik yang dibutuhkan. Agar teknik ini dapat diterapkan perlu ditetapkan parameter. Penelitian ini menggunakan 2 (dua) parameter dalam menetapkan responden. Pertama karakteristik responden yaitu dosen. Kedua harus pengguna facebook. Oleh karenanya penulis menggunakan online survey digunakan dalam pengumpulan data. Mekanismenya melalui penyebaran link Survey melalui grup diskusi yang ada di facebook yaitu melalui grup "Forum Dosen Muda Indonesia". Anggota grup adalah dosendosen yang tersebar diseluruh indonesia baik dari perguruan tinggi negeri maupun swasta. Berdasarkan online survey selama 1 (satu) bulan diperoleh 102 respon, namun data yang valid dan digunakan hanya sebanyak 84 responden.

Untuk sebaran usia, rata-rata responden berusia 24 s.d 34 tahun sebanyak $51 \%$ dan responden dengan usia35-44 tahun sebanyak 38\% (Gambar 2).

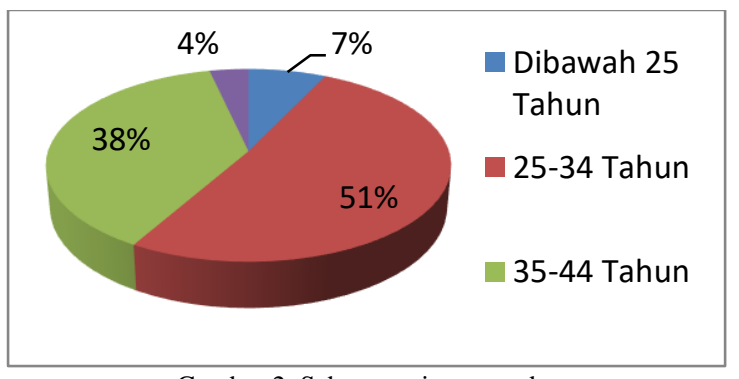

Gambar 2. Sebaran usia responden

Berdasarkan jenis kelamin, responden laki-laki sejumlah $42 \%$ dan $52 \%$ adalah responden perempuan (Gambar 3). Dari kriteria pendidikan, sebanyak $87 \%$ responden berpindidikan pascasarjana (S2), $7 \%$ pascasarjana (S3) dan 6\% Sarjana (Gambar 4).

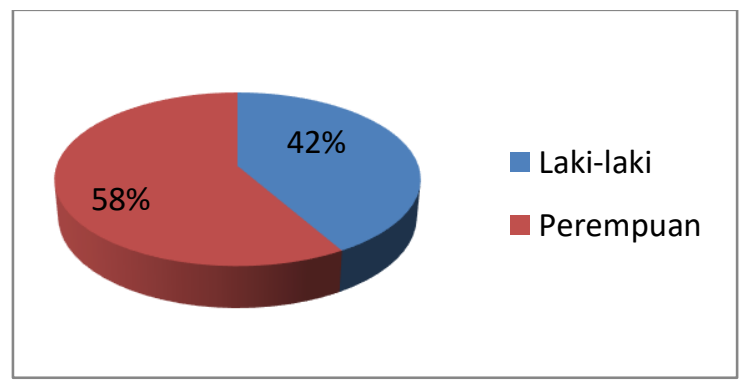

\subsection{Validasi Measurement model}

Gambar 3. Sebaran jenis kelamin responden

Untuk melakukan validasi model, dalam penelitian ini dilakukan validasi sesuai saran (Straub, Boudreau, \& Gefen, 2004), (Lewis, Templeton, \& Byrd, 2005) bahwa untuk validasi measurement model dilakukan validasi paling kurang meliputi : unidimensionality, internal consistency reliability, indicator reliability, convergent validity, dan discriminant validity.

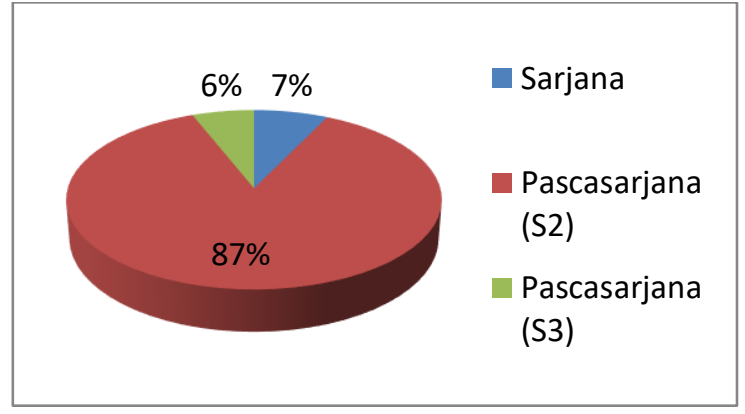

Gambar 4. Sebaran profil pendidikan responden

Tabel 1. Nilai indikator, means dan loading factor

\begin{tabular}{|c|c|c|}
\hline Indikator & Means & $\begin{array}{c}\text { Loading } \\
\text { Factor }\end{array}$ \\
\hline \multicolumn{3}{|l|}{ Confirmation $(C F)$ : } \\
\hline $\begin{array}{l}\text { CF1 : Pengalaman saya dengan } \\
\text { menggunakan Facebook sebagai } \\
\text { media informasi dan komunikasi } \\
\text { dengan mahasiswa lebih baik dari apa } \\
\text { yang saya harapkan. }\end{array}$ & 3.464 & 0.889 \\
\hline $\begin{array}{l}\text { CF2 : Tingkat layanan yang } \\
\text { disediakan oleh Facebook sebagai } \\
\text { media informasi dan komunikasi } \\
\text { dengan mahasiswa lebih baik dari apa } \\
\text { yang saya harapkan. }\end{array}$ & 3.393 & 0.890 \\
\hline $\begin{array}{l}\text { CF3 : Secara keseluruhan, sebagian } \\
\text { besar harapan saya dari menggunakan } \\
\text { Facebook sebagai media informasi } \\
\text { dan komunikasi dengan mahasiswa } \\
\text { terpenuhi. }\end{array}$ & 3.357 & 0.840 \\
\hline \multicolumn{3}{|l|}{ Continuance Intention $(\mathrm{CI})$ : } \\
\hline $\begin{array}{l}\text { CI1 : Saya berniat untuk terus } \\
\text { menggunakan Facebook sebagai } \\
\text { media informasi dan komunikasi } \\
\text { dengan mahasiswa di masa mendatang }\end{array}$ & 3.500 & 0.882 \\
\hline $\begin{array}{l}\text { CI2 : Saya akan selalu mencoba untuk } \\
\text { menggunakan Facebook sebagai } \\
\text { media informasi dan komunikasi } \\
\text { dengan mahasiswa dalam kegiatan } \\
\text { pembelajaran sehari-hari saya }\end{array}$ & 3.000 & 0.931 \\
\hline $\begin{array}{l}\text { CI3 : Dari semua pertimbangan, ada } \\
\text { kemungkinan bahwa saya akan terus } \\
\text { menggunakan Facebook sebagai } \\
\text { media informasi dan komunikasi } \\
\text { dengan mahasiswa selama kegiatan } \\
\text { pembelajaran. }\end{array}$ & 3.000 & 0.899 \\
\hline \multicolumn{3}{|l|}{ Satisfaction $(S F)$ : } \\
\hline $\begin{array}{l}\text { SF1 : Keseluruhan pengalaman saya } \\
\text { menggunakan Facebook sebagai } \\
\text { media informasi dan komunikasi } \\
\text { dengan mahasiswa sangat memuaskan }\end{array}$ & 3.464 & 0.877 \\
\hline $\begin{array}{l}\text { SF2 : Keseluruhan pengalaman saya } \\
\text { menggunakan Facebook sebagai } \\
\text { media informasi dan komunikasi } \\
\text { dengan mahasiswa sangat } \\
\text { menyenangkan }\end{array}$ & 3.429 & 0.877 \\
\hline $\begin{array}{l}\text { SF3 : Keseluruhan pengalaman saya } \\
\text { menggunakan Facebook sebagai } \\
\text { media informasi dan komunikasi } \\
\text { dengan mahasiswa merupakan ide } \\
\text { yang baik }\end{array}$ & 3.464 & 0.892 \\
\hline $\begin{array}{l}\text { SF4 : Keseluruhan pengalaman saya } \\
\text { menggunakan Facebook sebagai } \\
\text { media informasi dan komunikasi } \\
\text { dengan mahasiswa benar-benar } \\
\text { menyenangkan }\end{array}$ & 3.429 & 0.901 \\
\hline \multicolumn{3}{|l|}{ Service Quality $(S Q)$ : } \\
\hline $\begin{array}{l}\text { SQ1 : Saya merasa nyaman dalam } \\
\text { menggunakan fungsi dan layanan } \\
\text { yang diberikan oleh penyedia layanan }\end{array}$ & 3.429 & 0.796 \\
\hline
\end{tabular}




\begin{tabular}{|c|c|c|}
\hline Indikator & Means & $\begin{array}{l}\text { Loading } \\
\text { Factor }\end{array}$ \\
\hline \multicolumn{3}{|l|}{$\begin{array}{l}\text { Facebook sebagai media informasi } \\
\text { dan komunikasi dengan mahasiswa }\end{array}$} \\
\hline $\begin{array}{l}\text { SQ2 : Penyedia layanan Facebook } \\
\text { memberikan layanan dengan sepenuh } \\
\text { hati ketika kita menghadapi masalah } \\
\text { sistem. }\end{array}$ & 3.429 & 0.858 \\
\hline $\begin{array}{l}\text { SQ3 : Informasi yang diberikan oleh } \\
\text { penyedia Facebook sangat akurat dan } \\
\text { dapat dipercaya }\end{array}$ & 3.071 & 0.714 \\
\hline $\begin{array}{l}\text { SQ4 : Penyedia layanan Facebook } \\
\text { memberikan perhatian khusus }\end{array}$ & 3.250 & 0.830 \\
\hline $\begin{array}{l}\text { SQ5 : Penyedia layanan Facebook } \\
\text { memberikan layanan yang cepat }\end{array}$ & 3.321 & 0.825 \\
\hline \multicolumn{3}{|l|}{ Perceived Task Fit (TF) : } \\
\hline $\begin{array}{l}\text { TF1 : Menurut pendapat saya , fitur- } \\
\text { fitur Facebook cocok untuk membantu } \\
\text { saya menyebarkan informasi dan } \\
\text { berkomunikasi dengan mahasiswa } \\
\text { saya }\end{array}$ & 3.893 & 0.939 \\
\hline $\begin{array}{l}\text { TF2 : Menurut pendapat saya , fitur- } \\
\text { fitur Facebook cukup untuk } \\
\text { membantu saya menyebarkan } \\
\text { informasi dan berkomunikasi dengan } \\
\text { mahasiswa saya }\end{array}$ & 3.857 & 0.884 \\
\hline $\begin{array}{l}\text { TF3 : Menurut pendapat saya , fitur- } \\
\text { fitur Facebook cocok untuk kebutuhan } \\
\text { penyebaran informasi dan } \\
\text { berkomunikasi dengan mahasiswa } \\
\text { saya }\end{array}$ & 3.893 & 0.944 \\
\hline \multicolumn{3}{|l|}{ Utilization $(U L)$ : } \\
\hline $\begin{array}{l}\text { UT1 : Saya menggunakan Facebook } \\
\text { untuk menyediakan informasi tentang } \\
\text { pembelajaran/ perkuliahan. }\end{array}$ & 3.036 & 0.798 \\
\hline $\begin{array}{l}\text { UT2 : Saya menggunakan Facebook } \\
\text { agar informasi yang dibutuhkan } \\
\text { mahasiswa tersedia. }\end{array}$ & 3.286 & 0.868 \\
\hline $\begin{array}{l}\text { UT3 : Saya menggunakan Facebook } \\
\text { agar materi pembelajaran tersedia bagi } \\
\text { mahasiswa. }\end{array}$ & 3.071 & 0.863 \\
\hline $\begin{array}{l}\text { UT5 : Saya menggunakan Facebook } \\
\text { untuk memanfaatkan fasilitas pesan } \\
\text { untuk mengirim berita ke mahasiswa } \\
\text { saya. }\end{array}$ & 3.536 & 0.796 \\
\hline $\begin{array}{l}\text { UT6 : Saya menggunakan Facebook } \\
\text { untuk menerima laporan dari proyek/ } \\
\text { tugas mahasiswa. }\end{array}$ & 2.571 & 0.799 \\
\hline $\begin{array}{l}\text { UT7 : Saya menggunakan Facebook } \\
\text { untuk memanfaatkan dan membentuk } \\
\text { forum diskusi bagi mahasiswa saya. }\end{array}$ & 3.393 & 0.803 \\
\hline $\begin{array}{l}\text { UT8 : Saya menggunakan Facebook } \\
\text { untuk membentuk kelompok- } \\
\text { kelompok individu mahasiswa (closed } \\
\text { group). }\end{array}$ & 3.286 & 0.840 \\
\hline
\end{tabular}

Tabel 1. menyajikan hasil pengujian reliabilitas indikator. Seluruh indikator telah diuji, mengacu pada saran (Fornell, C., \& Larcker, 1981), semua indikator dikatakan signifikan jika nilai loading factor $>0.7$, bila ada indikator dengan nilai loading factor $<0.7$ indikator tersebut harus dihilangkan. Nilai loading factor menunjukkan besar korelasi indikator dengan konstruk latennya. Dalam penelitian ini terdapat 2 (dua) indikator dengan nilai loading factor $<0.7$ yaitu SQ6 dan UL4, maka kedua indikator ini harus dihilangkan. Berdasarkan data loading factor pada Tabel 1 dapat disimpulkan bahwa reliabilitas indikator telah tercapat. Artinya indikator dapat digunakan untuk mengidentifikasi konstruk penelitian.

Tabel 2. Hasil pengujian Reliability

\begin{tabular}{cccc}
\hline Construct & Cronbach & $\begin{array}{c}\text { Composite } \\
\text { Reliability }\end{array}$ & $\boldsymbol{A V E}$ \\
\hline CF & 0.845 & 0.906 & 0.763 \\
\hline CI & 0.888 & 0.931 & 0.818 \\
\hline SF & 0.910 & 0.937 & 0.787 \\
\hline SQ & 0.877 & 0.903 & 0.611 \\
\hline TF & 0.914 & 0.945 & 0.852 \\
\hline UT & 0.925 & 0.940 & 0.638 \\
\hline
\end{tabular}

Untuk validasi konsistensi internal dilakukan dengan menggunakan pengujian Cronbach Alpha (CA). Untuk pengujian $C A$ menurut (Cronbach, 1951); (Urbach \& Ahlemann, 2010) nilai $C A>0.800$. Tabel 2 memperlihatkan bahwa untuk semua konstruk memiliki nilai $C A>0.800$. hal ini menunjukkan bahwa semua konstruk telah memenuhi konsistensi internal. $C A$ digunakan untuk mengukur reliabitas instrumen. Berdasarkan pengujian $C A$, dapat disimpulkan bahwa instrumen handal untuk digunakan mendapatkan data. Selain dengan $C A$ reliabilitas konstruk juga diukur menggunakan Composite Reliability (CR). Jika CA menitikberatkan pada homogenitas, sedangkan $C R$ menitikberatkan pada identifikasi faktor umum. Hasil pengujian pada Tabel 2 menunjukkan nilai $C R$, semua konstruk memiliki nilai diatas $>0.900$, maka dapat disimpulkan bahwa reliabilitas kontruk telah terpenuhi, kesimpulan ini berdasarkan rekomendasi nilai $C R>0.700$. Sedangkan untuk pengujian validitas konvergen menggunakan nilai $A V E$. Nilai $A V E$ merepresentasikan validitas konvergen terpenuhi $(A V E>0.500)$, artinya bahwa satu variabel laten mampu menjelaskan lebih dari setengah varian dari indikator - indikatornya dalam rata-rata. Hasil pengujian memperlihatkan bahwa semua konstruk memiliki nilai $A V E>0.600$. Berdasarkan saran (Fornell, C., \& Larcker, 1981) nilai $A V E>0.500$.

Tabel 3. Hasil pengujian Discriminant Validities

\begin{tabular}{ccccccc}
\hline Cons- & \multicolumn{6}{c}{ Correlation of constructs } \\
\cline { 2 - 7 } truct & CF & CI & SF & SQ & TF & UT \\
\hline CF & $\mathbf{0 . 8 7 3}$ & & & & & \\
\hline CI & 0.684 & $\mathbf{0 . 9 0 4}$ & & & & \\
\hline SF & 0.799 & 0.817 & $\mathbf{0 . 8 8 7}$ & & & \\
\hline SQ & 0.689 & 0.667 & 0.707 & $\mathbf{0 . 7 8 2}$ & & \\
\hline TF & 0.674 & 0.588 & 0.762 & 0.661 & $\mathbf{0 . 9 2 3}$ & \\
\hline UT & 0.722 & 0.741 & 0.748 & 0.640 & 0.724 & $\mathbf{0 . 8 3 1}$ \\
\hline
\end{tabular}

Selanjutnya untuk menguji discriminant validity. Pengujian discrimant validity adalah untuk mengukur konstruk reflektif memiliki relasi yang kuat dengan indikatornya sendiri. Pada penelitian ini digunakan nilai cross-loading. (Chin, 1998) mengungkapkan "If the loading of each indicator is higher for its designated construct than for any of the other constructs, and each of the constructs loads highest with its own items, it can be inferred that the 
models' constructs differ sufficiently from one another". Berdasarkan pendapat chin tersebut maka dapat disimpulkan bahwa hasil pengujian pada Tabel 3. menunjukkan discriminant validity terpenuhi. Dengan kata lain pengujian validitas model terpenuhi atau model dapat digunakan untuk mengukur apa yang diinginkan, yaitu mengukur persepsi dosen terhadap kesesuaian dan kepuasan penggunaan facebook dalam perkuliahan.

\subsection{Validasi structural model}

Setelah melakukan validasi model, langkah selanjutnya untuk memvalidasi structural model. Untuk keperluan tersebut, pada penelitian ini dilakukan evaluasi path coeffecient dan coefficient of determination (R2).

\begin{tabular}{ccccc}
\multicolumn{5}{c}{ Tabel 4. Path analysis } \\
\hline \multicolumn{2}{c}{ Hypothesis } & T-statistic & P Value & Hasil \\
\hline H1 & TF->UT & $12.822^{*}$ & 0.000 & Diterima \\
\hline H2 & TF->CI & $2.823^{*}$ & 0.005 & Diterima \\
\hline H3 & TF->SF & $3.614^{*}$ & 0.000 & Diterima \\
\hline H4 & UT->CI & $4.394^{*}$ & 0.000 & Diterima \\
\hline H5 & CF->SF & $5.337^{*}$ & 0.000 & Diterima \\
\hline H6 & CF->TF & $11.256^{*}$ & 0.000 & Diterima \\
\hline H7 & SQ->SF & $2.157^{*}$ & 0.031 & Diterima \\
\hline H8 & SQ->CF & $12.302 *$ & 0.000 & Diterima \\
\hline H9 & SF->CI & $9.010^{*}$ & 0.000 & Diterima \\
\hline Significance
\end{tabular}

Significance : $* \mathrm{P}<0.01,{ }^{* *} \mathrm{p}<0.05$

Tabel 4. menyajikan hasil path analysis dari Gambar 1. Nilai path coeffisien dianggap signifikan jika memenuhi syarat t-values > 1.96 (Taneja, Vitrano, \& Gengo, 2014). Mengacu data pada tabel 4. memperlihatkan bahwa perceived task-fit, utilization dan satisfaction secara signifikan mempengaruhi continuance intention. Hal ini menunjukkan bahwa apabila seorang dosen merasa facebook yang digunakan sesuai dengan kebutuhan pekerjaan maka facebook tersebut akan terus digunakan, untuk membantu pekerjaan tersebut. Begitu pula, jika facebook dapat memenuhi utilitas pekerjaan, maka facebook akan terus digunakan. Apalagi jika penggunaan facebook dapat memuaskan pekerjaan, maka facebook akan digunakan secara terus menerus untuk mendukung pekerjaan. Hasil pengujian juga menunjukkan bahwa Perceived task fit , confirmation, dan Service quality secara signifikan mempengaruhi satisfaction. Dari pengujian ini dapat disimpulkan bahwa jika penggunaan facebook dirasakan sesuai untuk mendukung pekerjaan, dan penggunaan facebook dapat terkonfirmasi dapat membantu pekerjaan maka akan memenuhi kepuasan pengguna. Begitu juga halnya jika kualitas layananan facebook memenuhi ekspektasi pengguna, maka kepuasan akan tercapai. Selanjutnya hasil juga memperlihatkan adanya korelasi positif perceived task-fit dengan utilization, dan service quality dengan confirmation. Hal ini menunjukkan bahwa jika facebook dirasakan sesuai dengan pekerjaan yang diselesaikan maka utilisasi tercapai. Begitu pula halnya, jika kualitas layanan facebook memenuhi ekspektasi pengguna maka akan memicu konfirmasi.
Evaluasi coefficient of determination $(R$ Square) digunakan untuk mengukur seberapa besar varian variabel laten menjelaskan total variance nya (Urbach \& Ahlemann, 2010). Menurut (Chin, 1998), nilai mendekati 0.670 menunjukkan model "substantial", nilai sekitar 0.333 "moderate", dan nilai disekitar 0.190 menunjukkan model "weak". Mengacu pada gambar 2.3. hasil pengujian coefficient of determination, menunjukkan kontruk confirmation memiliki nilai $\mathrm{R}^{2}=0.436$, perceived task fit dengan nilai $R^{2}=0.456$, konstruk satisfaction mendapatkan nilai $\mathrm{R} 2=0.761$, continuance intention mendapatkan nilai $\mathrm{R}^{2}=0.723$ dan utilization dengan nilai $\left.\mathrm{R}^{2}=0.525\right)$. Berdasarkan hasil pengujian coeffecient of determination, konstruk continuance intention memperoleh nilai $\mathrm{R}^{2=} 0.723$, artinya bahwa persentase besarnya continuance intention dapat dijelaskan oleh satisfaction, perceived task fit dan utilization sebesar 72.3\%. Hal ini juga, membuktikan bahwa kemampuan model dalam penelitian ini dapat memprediksi kesesuaian dan kepuasan dosen terhadap menggunakan facebook dalam perkuliahan sebesar $72.3 \%$ yaitu termasuk dalam kategori subtansial.

\section{KESIMPULAN}

Pada penelitian sebelumnya telah diusulkan sebuah model untuk mengukur penggunaan teknologi secara berkelanjutan dengan mempertimbangkan kepuasan dan kesesuaian teknologi dengan pekerjaan. Pada model tersebut digunakan 5 (lima) buah konstruk yang dikembangkan dari model TTF dan ECT yaitu: perceived task fit, utilization, satisfaction, confirmation and service quality.

Berdasarkan hasil pengujian semua konstruk memiliki nilai $C A>0.800$, artinya semua konstruk telah memenuhi konsistensi internal. Pengujian $C R$ memperlihatkan semua konstruk memiliki nilai diatas $>0.900$, hal ini menunjukkan bahwa reliabilitas kontruk telah terpenuhi. Sedangkan untuk pengujian $A V E$, semua konstruk memiliki nilai $A V E>0.600$, disimpulkan bahwa reliabilitas kontruk telah terpenuhi. Hasil pengujian juga memperlihatkan discriman validity terpenuhi. Seluruh pengujian ini menunjukkan validasi measurement model terpenuhi atau model dapat digunakan untuk mengukur persepsi kesesuaian dan kepuasan terhadap penggunaan facebook pada perkuliahan.

Hasil pengujian hipotesis memperlihatkan perceived task-fit, utilization dan satisfaction secara signifikan mempengaruhi continuance intention. Hasil juga memperlihatkan bahwa Perceived task fit, confirmation, dan Service quality secara signifikan mempengaruhi satisfaction. Selanjutnya hasil juga memperlihatkan adanya korelasi positif perceived task-fit terhadap utilization, dan service quality terhadap confirmation.

Nilai $R$-Squre continuance intention pada penelitian adalah 0.723 , hal ini menunjukkan bahwa 
perentasi besarnya kemampuan model dalam memprediksi persepsi kesesuaian dan kepuasan dosen terhadap penggunaan facebook dalam perkuliahan sebesar $72.3 \%$.

Pada penelitian ini terdapat beberapa keterbatasan, sehingga perlu dilakukan pengembangan pada penelitian kedepan. Pertama. Penelitian ini menggunakan survey secara online, sehingga mendapatkan tingkat respon yang rendah. Dimana jumlah sampel tentu saja dapat mempengaruhi hasil analisa. Pada penelitian ini teidak mempertimbangkan efek mediasi seperti umur, jenis kelamin, dan lain-lain, dimana pada penelitianpenelitian yang berhubungan dengan adopsi teknologi mempertimbangkan hal tersebut. Penelitian ini hanya menggunakan faktor-faktor yang diadopsi dari teori ECT dan TTF, hal ini juga dapat mempengaruhi ketepatan model dalam memprediksi. Penelitian berikutnya harus mempertimbangkan faktor-faktor lain seperti : pengalaman internet, latar belakang pendidikan, pengalaman e-learning, dan latar belakang budaya. Selanjutnya, hal-hal lain yang dapat mempengaruhi penggunaan teknologi secara berkelanjutan harus dipertimbangkan.

\section{DAFTAR PUSTAKA}

ADAMOVIC, D., POTGIETER, A., \& MEARNS, M. (2012). Knowledge sharing through social media: Investigating trends and technologies in a global marketing and advertising research company. SA Journal of Information Management, 14(1), 1-7. https://doi.org/10.4102/sajim.v14i1.514

AKCAOGLU, M., \& DAVID, N. (2016). Using instructor-led Facebook groups to enhance students ' perceptions of course content. Computers in Human Behavior, 1-9. https://doi.org/10.1016/j.chb.2016.05.029

BHATTACHERJEE, A. (2001). Understanding Information Systems Continuance: An Expectation-Confirmation Model. Anol Bhattacherjee Source: MIS Quarterly, 25(3), 351-370. https://doi.org/10.2307/3250921

BUHI, E. R., GOODSON, P., \& NEILANDS, T. B. (2007). Structural Equation Modeling: A Primer for Health Behavior Researchers Objective : To introduce the state, 74-85.

CHEOK, M. L., \& WONG, S. L. (2015). Predictors of E-Learning Satisfaction in Teaching and Learning for School Teachers: A Literature Review. International Journal of Instruction, 8(1), 75-90.

CHIN, W. W. (1998). The Partial Least Squares approach to Structural.

CRONBACH, L. J. (1951). Coefficient Alpha and The Internal Structure of Tests. Psychometrika, 16(3), 297-334.

DELONE, W. H., \& MCLEAN, E. R. (2003). The DeLone and McLean Model of Information Systems Success : A Ten-Year Update, 19(4),
9-30.

DRAGANA, Z., ARSIC, S., MANASIJEVIC, D., \& MILOŠEVIC, I. (2015). Telematics and Informatics Facebook as virtual classroom Social networking in learning and teaching among Serbian students ` ivkovic, (February). https://doi.org/10.1016/j.tele.2015.02.003

FORNELL, C., \& LARCKER, D. F. (1981). (1981). Evaluating Structural Equation Models with Unobservable Variables and Measurement Error. Journal of Marketing, 18, 39-50.

GOODHUE, L., D., \& THOMPSON, R. L. (1995). Task-technology fit and individual performance, 3439 .

HERLAMBANG, A. D., \& HIDAYAT, W. N. (2016). Edmodo Untuk Meningkatkan Kualitas Perencanaan Proyek Dan Efektivitas Pembelajaran Di Lingkungan Pembelajaran Yang Bersifat Asinkron. Jurnal Teknologi Informasi Dan Ilmu Komputer, 3(3), 180. https://doi.org/10.25126/jtiik.201633193

HEW, K. F. (2011). Students ' and teachers ' use of Facebook, 27, 662-676. https://doi.org/10.1016/j.chb.2010.11.020

HOLZINGER, A., SEARLE, G., \& WERNBACHER, M. (2011). The effect of previous exposure to technology on acceptance and its importance in usability and accessibility engineering. Universal Access in the Information Society, 10(3), 245-260. https://doi.org/10.1007/s10209-010-0212-x

HOOPER, D., MULLEN, J., HOOPER, D., COUGHLAN, J., \& MULLEN, M. R. (2008). " Structural Equation Modelling: Guidelines for Determining Model Fit Structural Equation Modelling: Guidelines for Determining Model Fit. The Electronic Journal of Business Research Methods, 6(1), 53-60. Retrieved from www.ejbrm.com

KOPECKY, K. (2016). Telematics and Informatics Czech Children and Facebook - A quantitative survey q, 33, 950-958. https://doi.org/10.1016/j.tele.2016.02.008

KUMAR, S., JOSHI, A., \& SHARMA, H. (2016). A multi-analytical approach to predict the Facebook usage in higher education. Computers in Human Behavior, 55, 340-353. https://doi.org/10.1016/j.chb.2015.09.020

LAMBIC, D. (2016). Correlation between Facebook use for educational purposes and academic performance of students, 61, 313-320. https://doi.org/10.1016/j.chb.2016.03.052

LEWIS, B. R., TEMPLETON, G. F., \& BYRD, T. A. (2005). A methodology for construct development in MIS research, (May 2004), 388-400. https://doi.org/10.1057/palgrave.ejis.3000552

LIAO, C., CHEN, J. L., \& YEN, D. C. (2007). Theory of planning behavior (TPB) and customer satisfaction in the continued use of e- 
service: An integrated model. Computers in Human Behavior, 23(6), 2804-2822. https://doi.org/10.1016/j.chb.2006.05.006

LIN, W. S. (2012). Perceived fit and satisfaction on web learning performance: IS continuance intention and task-technology fit perspectives. International Journal of Human Computer Studies, 70(7), 498-507. https://doi.org/10.1016/j.ijhcs.2012.01.006

PATRICKS, A., LIBAQUE-SAENZ, C. F., FAN, S., \& CHANG, Y. (2016). Telematics and Informatics An expectation-confirmation model of continuance intention to use mobile instant messaging. TELEMATICS AND INFORMATICS, 33(1), 34-47. https://doi.org/10.1016/j.tele.2015.05.006

PETTER, S., DELONE, W., \& MCLEAN, E. (2008). Measuring information systems success: models, dimensions, measures, and interrelationships. European Journal of Information Systems, 17(3), 236-263. https://doi.org/10.1057/ejis.2008.15

PRADANA, F., RACHMADI, A., \& BACHTIAR, F. A. (2015). Penilaian Faktor Penerimaan Teknologi Blended learning di PTIIK Universitas Brawijaya dengan Metode Unified Theory of Acceptance and Use of Technology (UTAUT). Jurnal Teknologi Informasi Dan Ilmu Komputer, 2(1), 49. https://doi.org/10.25126/jtiik.201521130

SHIAU, W., HUANG, L., \& SHIH, C. (2011). Understanding Continuance Intention of Blog Users : A Perspective of Flow and Expectation Confirmation Theory, 6(4), 306-317. https://doi.org/10.4156/jcit.vol6.

SILIUS, K., KAILANTO, M., \& TERVAKARI, A. M. (2011). Evaluating the quality of social media in an educational context. International Journal of Emerging Technologies in Learning, 6(3), 21-27. https://doi.org/10.1109/EDUCON.2011.57731 83

STRAUB, D., BOUDREAU, M.-C., \& GEFEN, D. (2004). Validation Guidelines for IS Positivist Research Validation Guidelines for IS Positivist Research. The Communications of the Association for Information Systems, 13.1(c), 63.

TANEJA, A., VITRANO, J., \& GENGO, N. J. (2014). Rationality-based beliefs affecting individual's attitude and intention to use privacy controls on Facebook: An empirical investigation. Computers in Human Behavior, 38, 159-173. https://doi.org/10.1016/j.chb.2014.05.027

TESS, P. A. (2013). The role of social media in higher education classes ( real and virtual ) A literature review. Computers in Human Behavior, 29(5), A60-A68. https://doi.org/10.1016/j.chb.2012.12.032
URBACH, N., \& AHLEMANN, F. (2010). Structural Equation Modeling in Information Systems Research Using Partial Least Squares. Journal of Information Technology Theory and ..., 11(2). Retrieved from http://iris.ebs.edu/accessdb/WWW/iris_pub_w eb.nsf/wwwPublAuthorSingleEng/A58520D5 E3C484DCC1257C50007F8697/\$file/Urbach et al. 2010 Structural Equation Modeling in IS Research Using PLS.pdf

VENKATESH, V., THONG, J. Y. L., CHAN, F. K. Y., HU, P. J.-H., \& BROWN, S. A. (2011). Extending the two-stage information systems continuance model: incorporating UTAUT predictors and the role of context. Information Systems Journal, 21(6), 527-555. https://doi.org/10.1111/j.13652575.2011.00373.x

YEN, D. C., WU, C. S., CHENG, F. F., \& HUANG, Y. W. (2010). Determinants of users' intention to adopt wireless technology: An empirical study by integrating TTF with TAM. Computers in Human Behavior, 26(5), 906915. https://doi.org/10.1016/j.chb.2010.02.005

ZIVKOVI, D., ARSI, S., \& MILO, I. (2016). Exploring students' purposes of usage and educational usage of Facebook, 60 . https://doi.org/10.1016/j.chb.2016.02.087 